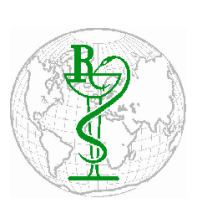

INDO GLOBAL JOURNAL OF

PHARMACEUTICAL SCIENCES

ISSN 2249- 1023

\title{
Microencapsulation of Nutraceuticals Using Spray Freeze Drying Method: A Brief Review
}

\author{
Rajeev Kumar ${ }^{*}$, Abhijit Kar \\ Division of Food and Post Harvest Technology, IARI, New Delhi, India
}

Address for Correspondance: Rajeev Kumar, rajeev.kumar267@gmail.com

\begin{abstract}
Microencapsulation is one of the quality preservation techniques of sensitive substances used in food and pharmaceutical industries. The process is practiced so far by many methods. Spray drying and Freeze drying are widely used methods. Spray-freeze-drying is relatively a newer technique that involves spraying a solution into a cold medium and removal of solvent (water) by conventional vacuum freeze drying method. The present study highlights the various aspects and previous study which have been carried out using spray freeze drying method in encapsulation.@ 2014 iGlobal Research and Publishing Foundation. All rights reserved.
\end{abstract}

KEYWORDS: Spray Freeze Drying; Encapsulation; Core Material; Matrix; Wall Material.

\section{INTRODUCTION}

Microencapsulation is the efficient technique of packing sensitive ingredients within a coating or wall material. The process is designed to protect the ingredients within coating material from moisture, oxidation, heat, light or extreme conditions during processing in an effort to increase their shelf life, and promoting the controlled liberation of the encapsulate (Shahidi \& Han, 1993). The concept of microencapsulation had its first inception in the late 1930 s as a cleaner substitute for carbon paper and carbon ribbons as sought by the business machines industry but the application of spray freeze drying in microencapsulation came into exist since 1999.

The concept of microencapsulation is equally applicable to agriculture, food, pharma, biotechnology and textile industry. As far as food industry is concerned microencapsulated products have found many applications as to coat colorants, flavors, vitamins, and other sensitive food ingredients in order to increase their shelf life (Dziezak, 1988; Shahidi \& Han, 1993). In the food industry, the microencapsulation process can be applied for a variety of reasons, which have been summarized by Desai \& Park (2005) as follows: (i) protection of the core material from degradation by reducing its reactivity to its outside environment; (ii) reduction of the evaporation or transfer rate of the core material to the outside environment; (iii) modification of the physical characteristics of the original material to allow easier handling; (iv) tailoring the release of the core material slowly over time, or at a particular time; (v) to mask an unwanted flavor or taste of the core material; (vi) dilution of the core material when only small amounts are required, while achieving uniform dispersion in the host material; (vii) to help separate the components of the mixture that would otherwise react with one another.

Spray freeze drying method usually carried out by spraying a solution containing dissolved/suspended material (e.g. protein) by an atomization nozzle into a cold vapor phase of a cryogenic liquid, such as liquid nitrogen, so the droplets may start freezing during their passage through the cold vapor phase, and completely freeze upon contact with the cryogenic liquid phase The frozen droplets are then dried by lyophilization. This method combines the narrow particle size distribution of an extrusion device and the freeze-drying process to prepare a dry powder of desired particle size and of narrow distribution.The pharmaceutical industry utilized recently the spray freeze drying for pharmaceutical powders preparation (Costantino et al., 2000, 2002; Maa and Prestrelski, 2000; Maa et al., 1999; Webb et al., 2002; Yu, Johnston, \&Williams, 2006).

The application of spray freeze drying method in microencapsulation have been studied by different research workers. The method were found superior to spray drying and 


\section{Indo Global Journal of Pharmaceutical Sciences, 2014; 4(2): 47-51}

freeze drying when comparative study facilitated. Therefore the present study undertaken with the objective to highlighting the previous study of microencapsulation using spray freeze drying method.

\section{Encapsulating agent}

The microencapsulation process involves entrapment of a core material, usually a liquid but can be a solid or gas, or a mixture into a coating material. The coating material can also be called the capsule, wall material, membrane, carrier or shell (Kibry, 1991). The different wall materials commonly compromising of gums, celluloses, starches and proteins (Jackson \& Lee, 1991). Starches are abundant and cheaper encapsulating agents than other materials, used to protect encapsulated ingredients from oxidation (Shahidi \&Han, 1993), prevents the loss of volatile ingredient, and also controls release of the ingredient (Risch, 1993; Shahidi \& Han, 1993). Modified and hydrolyzed starches owing better properties over native starches as coating materials. Hydrolyzed starches, which can be obtained using acids or specific enzymes, are common encapsulating agents because these materials are low in cost, have a bland flavor and provide good flavor protection against oxidation (Wagner \& Warthesen, 1995); however, hydrolyzed starches present poor emulsification properties (Reineccius, 1988). Maltodextrins are hydrolyzed starches, have been reported as effective wall material in combination with whey protein and emulsifier Tween 80 to encapsulate ethyl caprylate (Sheu \& Rosenberge, 1995) and bixin (Barbosa, Borsarelli \& Mercadante 2005) respectively.

\section{Encapsulation methods}

Various techniques are employed so far to microencapsulate food ingredients including spray drying, liposome entrapment, coacervation, gelation, emulsion phase separation. Spraydrying is the most often used technique in the food industry (Gibbs et al., 1999; Reineccius, 1988). Spray drying method helps in low process cost, wide choice of coating material, good encapsulation efficiency and stability of the finished product, possibility of large scale production in continuous mode but facilitating encapsulation of highly temperature sensitive compounds and control of the particle size using this method is difficult. Spray freeze drying could be an efficient method to preserve highly temperature sensitive due to its low temperature operation compared to spray drying.

\section{Encapsulate Type}

There are generally two types of encapsulates might be occurred after the encapsulation process i.e., the reservoir type and the matrix type. The reservoir type has a shell around the active agent. This type is also called capsule, single-core, mono-core or core-shell type. Application of pressure can lead to breakage of the reservoir type of encapsulates and thus to the release of its contents. Poly- or multiple-core type of encapsulates with several reservoir chambers in one particle also exist. The active agent in the matrix type is much more dispersed over the carrier material; it can be in the form of relatively small droplets or more homogenously distributed over the encapsulate. For simplification, Fig. 1 shows only spherical shaped encap- sulates, but they can also be cylindrical, oval or irregular shaped (gibbs et al., 1999).
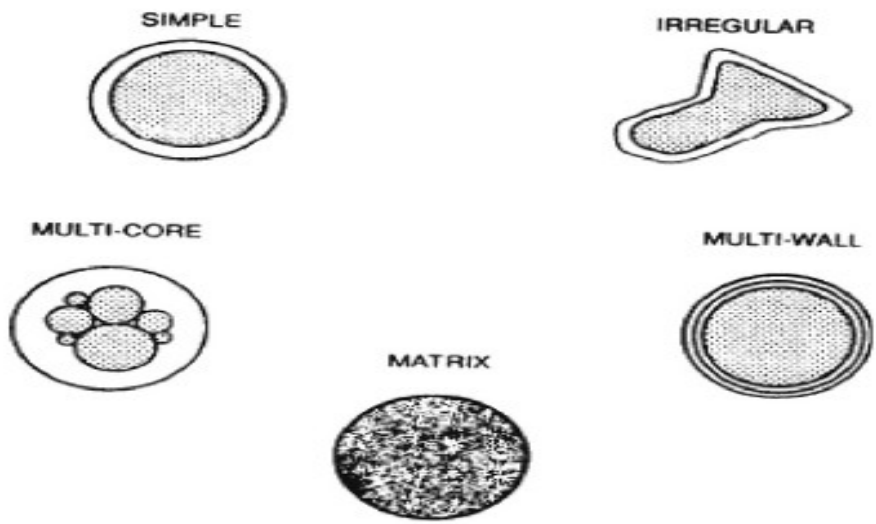

Fig. 1 Type of different type of microencapsulate

\section{SPRAY FREEZE DRYING METHOD}

The process is carried out in a two-stage operation (Fig. 2). The first step involved spray-freezing in which continuously homogenized sample fed into two fluid nozzles with the help of peristhetic pump. Each nozzles are attached by peristhetic pump at one end and with compressed air to another end. The outlet of the nozzle was positioned about $10 \mathrm{~cm}$ above liquid nitrogen. In the second step the resulting suspension (frozen droplets of the solution in liquid nitrogen) was transferred into the freeze dryer. Vacuum applied as soon as all nitrogen was evaporated. During the first 24 hours the pressure was set at $0.220 \mathrm{mbar}$ and the shelf temperature at $-35^{\circ} \mathrm{C}$. During the second 24 hours, the shelf temperature gradually raised to $20^{\circ} \mathrm{C}$ while the pressure decreased to 0.05 mbar. After removing the samples from the freeze drier, samples should properly stored over silica gel in a vacuum desiccators at room temperature for at least 1 day.

\section{Application of Spray-Freeze-Drying}

The application of spray freeze drying in encapsulation was observed by Drooge et al., 2005 by spray freeze dried the solutions of tetrahydrocannabinol (THC-a pharmacologically active constituent of the cannabis sativa) and inulin in a mixture of tertiary butanol (TBA) and water were. The study was found to prevent it from readily oxidation upon contact with air and degradation in aqueous solutions especially at low $\mathrm{pH}$ and maintaining its analgesic, anti-inflammatory, anxiolytic, bronchodilative, hypotensive, spasmolytic and intraocular pressure reducing activity. The spray freeze drying method was found to be for the effectively stabilised of tetrahydrocannabinol than by freeze drying. 
Indo Global Journal of Pharmaceutical Sciences, 2014; 4(2): 47-51

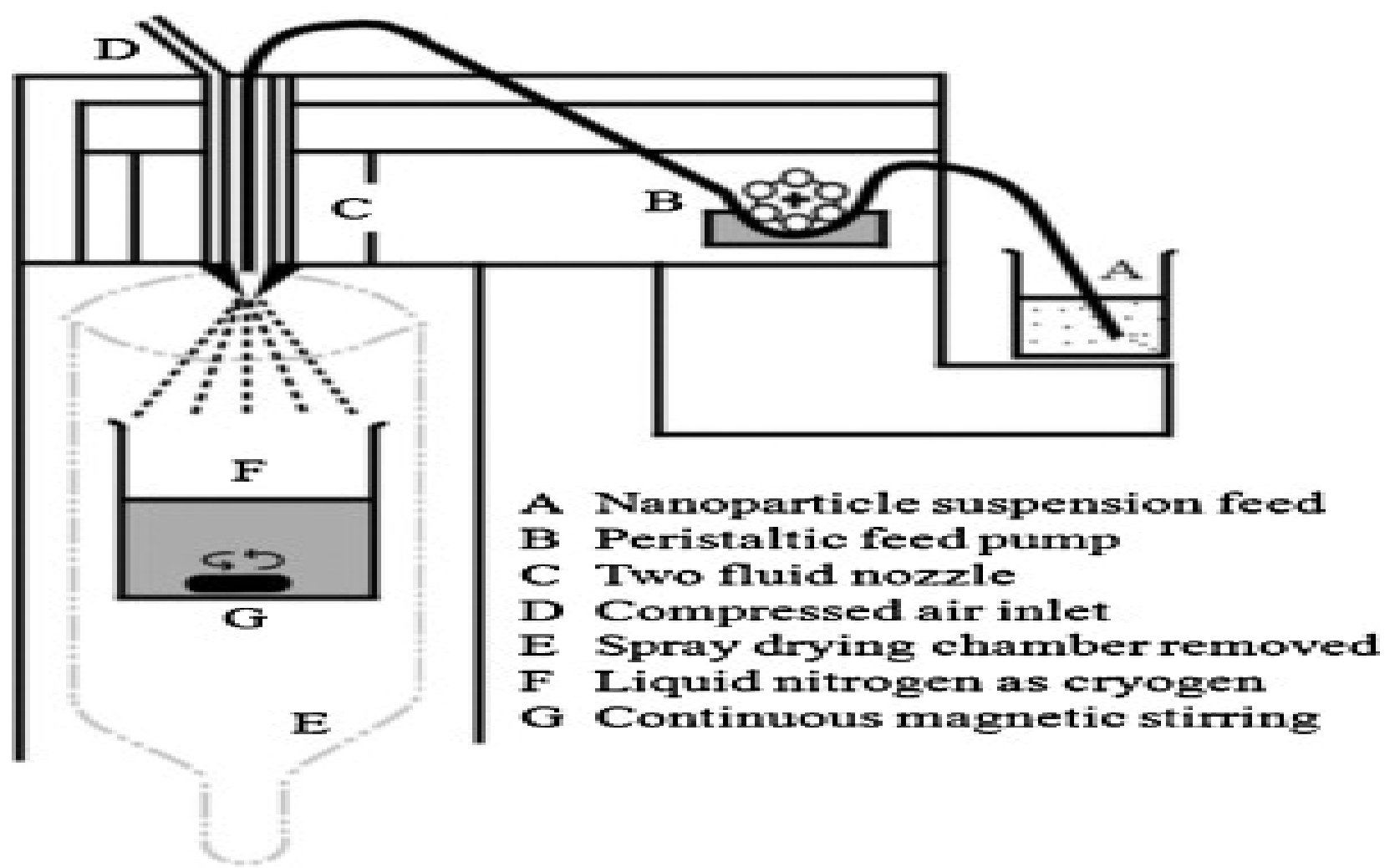

Fig. 2 Schematic diagram of Spray freeze drying method

Table 1 Other methods of encapsulation and their process steps, morphology and particle size

\begin{tabular}{|c|c|c|c|}
\hline Method & Process steps & Morphology & $\begin{array}{c}\text { Particle } \\
\text { size }(\mu \mathrm{m})\end{array}$ \\
\hline Spray drying & $\begin{array}{l}\text { 1. Disperse or dissolve active in aqueous coating solution } 2 \text {. Atomize } 3 . \\
\text { Dehydrate }\end{array}$ & matrix & $10-400$ \\
\hline Fluid bed coating & 1. Fluidize active powder 2. Spray coating 3. Dehydrate or cool & reservoir & $5-5500$ \\
\hline Spray-chilling/ cooling & 1. Disperse or dissolve active in heated lipid solution 2. Atomize 3. Cool & matrix & $20-200$ \\
\hline Melt injection & $\begin{array}{l}\text { 1. Melt the coating } 2 . \text { Disperse or dissolve active in the coating } 3 . \\
\text { Extrude through filter } 4 \text {. Cooling and dehydrating }\end{array}$ & matrix & $200-2000$ \\
\hline Melt extrusion & $\begin{array}{l}\text { 1. Melt the coating } 2 \text {. Disperse or dissolve active in the coating } 3 . \\
\text { Extrude with twin-screw extruder } 4 \text {. Cool }\end{array}$ & matrix & $300-5000$ \\
\hline Emulsification & $\begin{array}{l}\text { 1. Dissolve active and emulfiers in water or oil phase } 2 \text {. Mix oil and } \\
\text { water phases under shear }\end{array}$ & matrix & $0.2-5000$ \\
\hline Coacervation & $\begin{array}{l}\text { 1. Prepare } \mathrm{o} / \mathrm{w} \text { emulsions with lipophilic active in oil phase } 2 \text {. Mix under } \\
\text { turbulent conditions } 3 \text {. Induce three immiscible phases } 4 \text {. Cool } 5 \text {. } \\
\text { Crosslink (optionally) }\end{array}$ & Reservoir & $10-800$ \\
\hline Liposome entrapment & $\begin{array}{l}\text { 1. Disperse lipid molecules in water, with active agent in lipid or water } \\
\text { phase } 2 \text {. Reduce size by high shear or extrusion } 3 \text {. Remove free active } \\
\text { (option) }\end{array}$ & Various & $10-1000$ \\
\hline $\begin{array}{l}\text { Encapsulation by rapid expansion } \\
\text { of supercritical fluid (RESS) }\end{array}$ & $\begin{array}{l}\text { 1. Create a dispersion of active and dissolved or swollen shell material in } \\
\text { supercritical fluid } \\
\text { 2. Release the fluid to precipitate the shell onto the active }\end{array}$ & matrix & $10-400$ \\
\hline Freeze drying & $\begin{array}{l}\text { 1. Dissolve or disperse active agent and carrier material in water } \\
\text { 2. Freeze the sample } 3 \text {. Drying under low pressure } 4 \text {. Grinding (option) }\end{array}$ & matrix & $20-5000$ \\
\hline $\begin{array}{l}\text { Preparation of microspheres via } \\
\text { emulsification }\end{array}$ & $\begin{array}{l}\text { 1. Emulsify water with biopolymer in oil phase } \\
\text { 2. Add gelling agent under shear }\end{array}$ & matrix & $10-1000$ \\
\hline $\begin{array}{l}\text { Preparation of microspheres via } \\
\text { extrusion or dropping }\end{array}$ & $\begin{array}{l}\text { 1. Dissolve or disperse active in alginate solution } \\
\text { 2. Drop into gelling bath }\end{array}$ & matrix & $200-5000$ \\
\hline coextrusion & 1. Dissolve or disperse active in oil & reservoir & $150-8000$ \\
\hline
\end{tabular}


Indo Global Journal of Pharmaceutical Sciences, 2014; 4(2): 47-51

(Zuidam and Shimoni, 2010)

2. Prepare aqueous or fat coating

3. Use an concentric nozzle, and press simultaneously the oil phase throus the inner nozzle and the water phase through the outer one 4. Drop into gelling or cooling bath

(a)

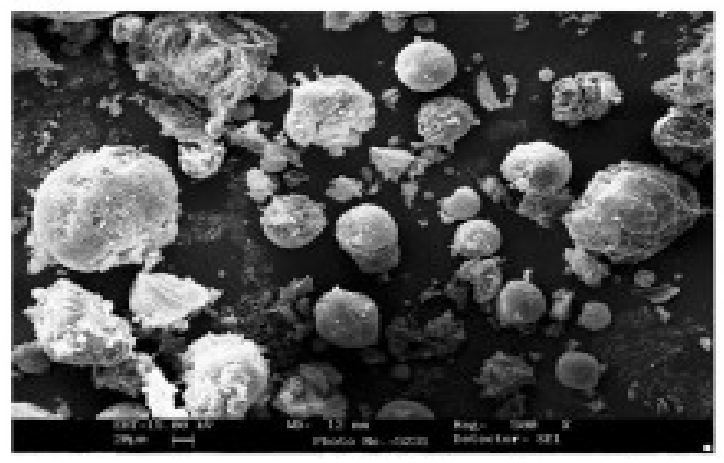

(b)

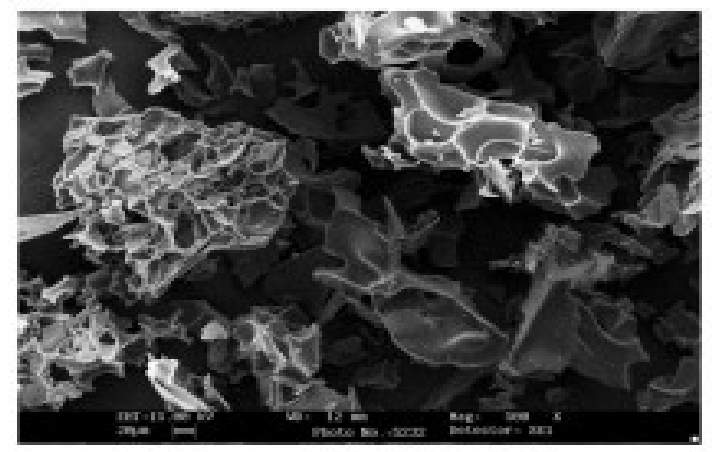

Fig .3 SEM analysis of spray freeze dried microencapsulated probiotic

A study carried out consisting of sample of solid dispersions of baicalein and a carrier with a low glass transition/melting point (Pluronic F68) and prepared by spray freeze drying. Scanning electro microscopic and Xray diffraction results suggested that the majority of baicalein in the spray freeze dried processed solid dispersion was in the amorphous state, which has a higher specific surface area than pure baicalein (Zheng et al., 2011).

The microencapsulation of docosahexaenoic acid (DHA) was investigated using spray freeze drying, spray drying and freeze drying by Karthik, P. and Anandharamakrishnan, C. (2013). Spray Freeze dried method yielded microencapsulated DHA with lower peroxidation (protected from oxidation) than Freeze dried and spray dried methods. Storage study indicated that Spray Freeze Dried microencapsulated powders showed lower peroxidation than Freeze dried and Spray Dried encapsulated powders. The morphological study of sprayfreeze-dried samples depicted spherical shape with fine pores on the surface, while spray dried process yielded spherical shape without pores, which in turn resulted in good rehydration behavior of the Spray Freeze Dried powdered product.

The microencapsulation using spray freeze drying have been successfully studied for the development of prebiotics as of Lactobacilus plantarum (Dolly et al., 2011) and Lactobacilus paracasei (Semyonov et al., 2010). Microencpasulation of various bacterial cultures including probiotics has been a common practice for extending their storage life and converting them into a powder form for ease of their use. The study of Semyonov et al., 2010 (Fig 1.3) concentrated on determining the survival of the cells, encapsulated in a matrix of maltodextrin and trehalose. Spray Freeze Drying was compared with the conventional freeze drying. Overall it was shown that Spray Freeze Drying is a successful method to generate dry micro-capsules of probiotic cells with high viability $(>60 \%)$.

\section{CONCLUSON}

Microencapsulation using spray freeze drying can be successfully achieved and it can be very useful than other method of encapsulation especially for heat sensitive ingredients. Spray freeze drying can be a longer process because of inclusion of freeze drying in it, but it is also helpful in maintaining desirable particle size. Due to these properties this method could be helpful to encapsulate various food and pharma ingredients.

\section{REFERENCES}

1. Barbosa MIMJ, Borsarelli C D, and Mercadante AZ. Light stability of spray-dried bixin encapsulated with different edible polysaccharide preparations. Food Research Int 2005, 8: 989-994.

2. Costantino HR, Firouzabadian L, Hogeland $\mathrm{K}, \mathrm{Wu} \mathrm{C}$, Beganski C, Carrasquillo KG, Córdova M, Griebenow K, Zale SE, and Tracy M A. Protein spray-freeze-drying. Effect of atomization conditions on particle size and stability. Pharmaceutical Research, 2000. Vol. 17(11), pages 1374-1383.

3. Costantino HR, Firouzabadian L, Wu CC, Carrasquillo KG, Griebenow K, Zale SE, and Tracy MA. Protein sprayfreeze-drying. Effect of formulation variables on particle size and stability. J. of Pharmaceutical Sci, 2002.Vol. 91(2), pages 388-395.

4. Desai KGH, and Park HJ. Recent development in microencapsulation of food ingredients. Drying Tech, 2005. 29: 1361-1394. 
Indo Global Journal of Pharmaceutical Sciences, 2014; 4(2): 47-51

5. Drooge DJ V, Hinrichs WLJ, Dickhoff BLJ, Elli MNA, Visser MR, Zijlstra GS, and Frijlink HW. Spray freeze drying to produce a stable $\Delta$ 9-tetrahydrocannabinol containing inulin- based solid dispersion powder suitable for inhalation. Eur. J. of Pharm. Sci, 2005, 26(2), 231-240.

6. Dziezak JD. Microencapsulation and encapsulated ingredients. Food Tech, 1988, 42(4): 136-151.

7. Gibbs BF, Kermasha S, Alli I, and Mulligan N. Encapsulation in the food industry: A review. Int Jof Food Sci and Nut, 1999, 50: 213-224.

8. Jackson LS, and Lee K. Microencapsulation and food industry. LWT - Food Sci and Tech, 1991, 24: 89-297.

9. Karthik P, Anandharamakrishnan C. Microencapsulation of Docosahexaenoic Acid by Spray-Freeze-Drying Method and Comparison of its Stability with Spray-Drying and Freeze-Drying Methods. Food and Bioprocess Tech, 2013, Volume 6; pp 2780-2790.

10. Kibry C, "Microencapsulation and controlled delivery of food ingredients", J. Food Sci. Tech, 1991, vol. 5, pp. 7478.

11. Maa YF, Prestrelski S J. Biopharmaceutical powders particle formation and formulation considerations. Current Pharmaceutical Biotech, 2000, 1(3): 283-302.

12. Maa YF, Nguyen PA, Sweeney T, Shire S J, Hsu CC. Protein inhalation powders:Protein inhalation powders: spray-drying vs spray-freeze-drying. Pharmaceutical research, 1999, Vol. 16(2): 249-254.

13. Priyanka Dolly P, Anishaparvin A, Joseph GS, Anandharamakrishnan C. Microencapsulation of Lactobacillus plantarum (mtcc 5422) by spray-freezedrying method and evaluation of survival in simulated gastrointestinal conditions, 2011, Informa health care.

14. Risch JR. Encapsulation: Overview of uses and techniques. In S. J. Risch, \& G. A. Reineccius (Eds.), Encapsulation and controlled release of food ingredients, 1993, ACS
Symposium Series, 590 (pp. 3-7). Washington, DC: American Chemical Society.

15. Reineccius GA. Spray-drying of food flavors. In S. J. Risch, \& G. A. Reineccius (Eds.), Flavor encapsulation. ACS Symposium Series, 1988, 370 (pp. 55-66). Washington, DC: American Chemical Society.

16. Semyonov D, Ramon O, Kaplun Z, Levin-Brener L, Gurevich N, Shimoni E. Microencapsulation of Lactobacillus paracasei by spray freeze drying. Food Research Int, 2010, 43: 193-202.

17. Shahidi F, Han XQ. Encapsulation of food ingredients. Critical Review of Food Sci and Nut., 1993, 33(6), 501547.

18. Sheu TY, Rosenberge M. Microencapsulation by spray drying ethyl caprylate in whey protein and carbohydrate wall systems. J. of Food Sci, 1995, 60(1), 98-103.

19. Yu ZS, Johnston KP, Williams RO. Spray freezing into liquid versus spray-freeze drying: Influence of atomization on protein aggregation and biological activity. Eur $\mathrm{J}$ of Pharmaceutical Sci, 2006, 27(1): 9-18.

20. Wagner LR, Warthesen JJ. Stability of spray-dried encapsulated carrot carotenes. J of Food Sci, 1995, 60(5), 1048-1053.

21. Webb SD, Cleland JL, Carpenter JF, Randolph TW. A new mechanism for decreasing aggregation of recombinant human interferongamma by a surfactant: Slowed dissolution of lyophilized formulations in a solution containing $0.03 \%$ polysorbate 20 . J of Pharmaceutical Sci, 2002, 91(2), 543-558.

22. Zheng He, Pei Tong. Comparison of Spray Freeze Drying and the Solvent Evaporation Method for Preparing Solid Dispersions of Baicalein with Pluronic F68 to Improve Dissolution and Oral Bioavailability . $\underline{\text { AAPS }}$ PharmSciTech, 2011, Volume 12, Issue 1, pp 104-113.

23. Zuidam NJ, Shimoni E. Encapsulation Technologies for Active Food Ingredients and Food Processing, 2010. ID: 101610675) indexed and abstracted in EMBASE(Elsevier), SCIRUS(Elsevier),CABI, CAB Abstracts, Chemical Abstract Services(CAS), American Chemical Society(ACS), Index Copernicus, EBSCO, DOAJ, Google Scholar and many more. For further details, visit 